\title{
Determining Urban Emotions: A Case Study around Majitar, East District, Sikkim
}

\author{
Supriya Choudhury \\ Sikkim Manipal University \\ Dept. of CSE, SMIT \\ Majitar, Sikkim
}

\begin{abstract}
Perception and expectation of citizens is an important factor in urban settlement, planning and management. Hence, there is a need of a participatory citizen centric planning of urban settlement based on spatial data. These perception and expectation may be represented in terms of emotions. Determining Urban Emotions is an approach which can be used to map different types of emotions associated with urbanization. In the recent years, some new methods have been presented for the area of urban and spatial planning, which resulted in a fundamental change of the issues and understanding of urban planning. Geographical information system acts as a key factor for analyzing urban emotions from various types of data. This paper presents the supervised learning approach for determining urban emotions using KNearest Neighbor algorithm.
\end{abstract}

\section{Keywords}

Urban Planning, Spatial Planning, Smart City, Urban Emotions, K-Nearest Neighbor Algorithm.

\section{INTRODUCTION}

An Urban Emotion is one of the emerging approaches that combine the concepts of spatial planning, geographic information systems, computer linguistics, sensor technology methods and real world data, where spatial planning considers all social and spatial structures within the city and helps in collecting various forms of data in context to the city. It involves both the spatial and temporal patterns that help in research activities in identifying processes and to characterize special social-cultural movements and developments. Geographic information system consists of two distinct disciplines geography and information system. It is an information system designed to work with data that are referenced by spatial or geographical coordinates. Computer linguistics is an interdisciplinary field concerned with the statistical or rule based modeling of natural language from a computational perspective. Real world data is an umbrella term used for different types of data that are collected in conventional randomized controlled trials. It can be technical sensor data, crowd sourced data, human- sensor data or social data, etc. It can be used for decision making.

The main idea behind this approach is the involvement of people of a particular location into various planning processes. Urban Emotion deals with different expectations of people regarding a particular location and what additional features can be added to the locality. It explains the potentiality of integrating objectively quantifiable emotions in context of citizen participation. Determination of Urban Emotion figures out the use of real world data.
Citizen's perception and urban space when linked together triggers an emotional reaction and creates its own atmosphere in the observer. Urban emotion aims to understand how people's feelings get affected by features of the current environment, green spaces, air pollution, water pollution, noise pollution, affects of industrialization, land degradation, road condition, and other geographical factors.

Better urban planning approaches are needed to build a city into a smart city. Smart cities are the cities that are able to operate in a sustainable, efficient and intelligent manner and require smart infrastructure with advanced sensing capabilities that extend beyond mere technical subtitles, thereby possibly benefitting architects and citizens of the cities. It means smart citizens can make intelligent cities. It relies on the idea that only citizens can make a city really intelligent. It needs to be tackled both from technological view point and human centric view point that a city requires smart citizens to be intelligent themselves.

\section{PROBLEM DEFINITION}

People's feelings and emotions generally changes with the geographical location. How people gain perception with context to the city is always been an issue in urban planning and management. The problems of considering subjective measurements and views provided by the citizens by involving them into planning processes represent great challenges for efficient urban planning. The wide range of the problems of extracting human emotion in context to the city may make good understanding of different expectation of the people. Assessing human emotions with relation to various geographical data is an important issue in urban planning. Urban Emotion adds a new information layer which will help in urban planning.

\section{PROPOSED APPROACH}

To solve this problem, we will be using different types of data of different facilities that are considered to be essential for urban planning and settlements. This case study is conducted for better understanding of the developments that took place so far in context to each facility, what are the different expectation of the people regarding each facility, how much people are emotionally attached to that location, how much knowledge do they have regarding Majitar location, what additional features and developments they want in that locality.

Urban emotions can be categorized by studying the demands of the individuals availing the following six facilities:

(i) Educational Facility

(ii) Entertainment Facility

(iii) Health Facility 
(iv) Industrialization Facility

(v) Shopping Mart Facility

(vi) Transportation Facility

We can determine urban emotion using the following approach:

Step1. Find and determine the types of emotions to be analyzed.

Step2. Building up questionnaires for emotions.

Step3. Determination and expression of emotions by the Sample Data Set.

Step4. Determining relationship between emotions by analysis of the expressions using a computational technique.

\section{METHODOLOGY USED}

The k-nearest neighbor (KNN) classifier is a type of supervised machine learning approach and a non-parametric lazy learning algorithm where, non-parametric means it does not make any assumptions on the underlying data distribution and lazy means it does not use the training data points to do any generalization. The lack of generalization means it keeps all the training data which are needed during the testing phase. Its training phase is pretty fast. It makes decision based on entire training data set (in the best case a subset of them). It is versatile and very simple to understand but it works incredibly well in practice.

It classifies data objects (or cases) based on their similarity to other data objects. In machine learning, it is used to recognize patterns of data without requiring an exact match to any stored patterns, or cases. Similar near each other and dissimilar objects are distant from each other. Thus, the distance between two objects (or cases) is a measure of their dissimilarity. The data objects that are near each other are said to be "neighbors". A new data objects are termed as holdout and are used for testing purpose. Whenever a new data object (case) is presented, its distance from each of the objects (cases) in the model is computed. The classification of the most similar objects (or cases or nearest neighbors) are tallied and the new object case is placed into the class (or category) that contains the greatest number of nearest neighbors.

For supervised learning, we have split the dataset of size 100 is split into two parts: $50 \%$ training and 50\% testing (or holdout). There are some assumptions that are followed before using this algorithm. It is assumed that the data is in a feature space; they have a notion of distance which can be a commonly used Euclidean distance. The basic KNN computes the similarity measure based on this distance measure. This metric makes KNN very sensitive to noisy features. Each of the training data consists of a set of object (or features) and class label associated with each object. KNN can work equally well with arbitrary number of classes. It consists of a single number $(\mathrm{k})$ which decides how many neighbors (that are defined based on the distance metric) influence the classification. If $\mathrm{k}=1$, it is simply called as the Nearest Neighbor algorithm.

The main objective is to find the ' $\mathrm{k}$ ' training samples in order to the k-nearest neighbors based on a distance measure, that is, Euclidean Distance. For that purpose, we sort the distances of all training samples to the new instance using Quick Sort algorithm and determine the kth minimum distance. For data classification [11], we find the majority of the category (or class) of k-nearest neighbors. Then, we perform ranking and categorization of new data points (or objects) [11].

K-nearest neighbor Algorithm:

1. Determine the ' $\mathrm{k}$ ' number of neighbors.

2. Calculate the distances between the new input data and all training data using Euclidean distance [11].

3. Sort the distances and determine ' $\mathrm{k}$ ' nearest neighbors based on the $\mathrm{k}^{\text {th }}$ minimum distance [11].

4. Gather the categories (or classes) of those neighbors.

5. Determine the category (or class) based on majority vote.

\section{CASE STUDY AREA}

The methodology is implemented in the Majitar. It is a small village in East District of Sikkim, located at $27.1894^{\circ} \mathrm{N}$ $88.4978^{\circ} \mathrm{E}$. The nearest towns to Majitar are Rangpo (4 km away) and Singtam (7 km away) as shown in figure 1 and figure 2. It is about 200 metres (660 ft) above sea level which gives it a sub-tropical climate [12].

Due to its geographic location and low population density, it has been considered to have less urban settlements and development. Majitar is largely populated by Nepalese people, Bhutia people, Marwari people, and Bengali people. Nepali language is the predominant language but some people speak Hindi too.

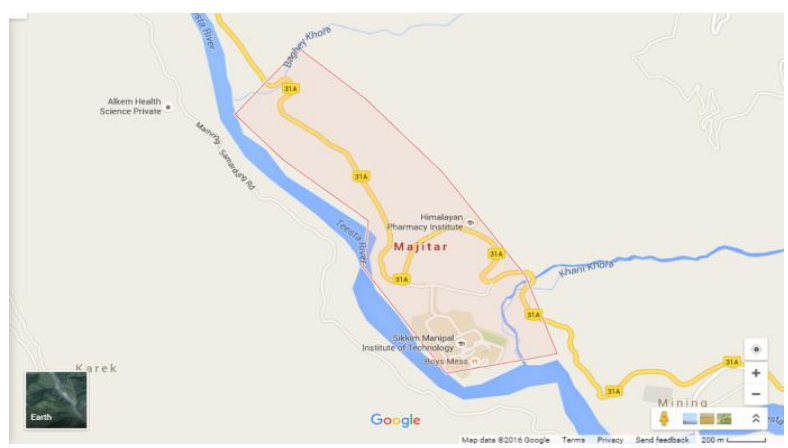

Fig 1: Map of Majitar (Source: Google Maps)

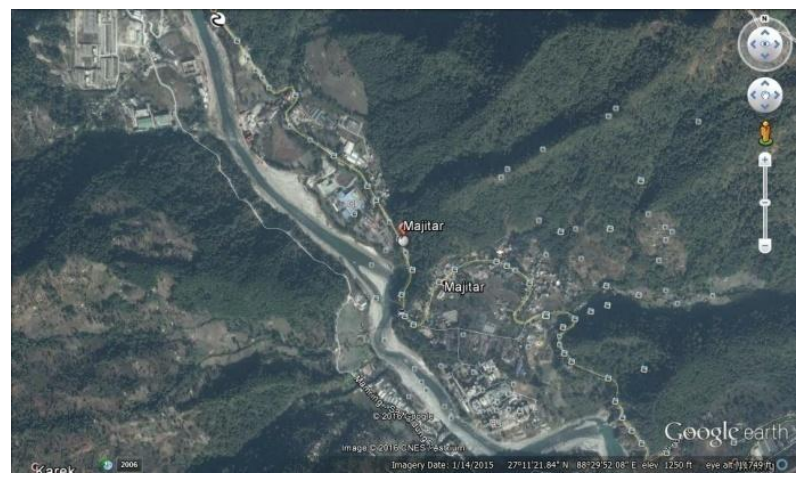

Fig 2: Map of Majitar (Source: Google Earth)

\section{RESULTS}

For the implementation, we have prepared a set of questionnaires for each facility. The number of questions varies from 10-12 numbers for each facility. The responses to each questions need to be provided in the range of 1-10 for specifying the quantities. Some questions require the responses in the form of nominal values such as worst, bad, average, good and better for better understanding of present 
condition and scenarios of each facility. And few questions required to be answered as yes or no. Then, we have collected data from 100 people of age group 15-60 residing in Majitar locality by conducting a survey. We have prepared a dataset of range 1 to 100 . Out of 100 people, 66 responses are provided by male participants and 34 are provided by female participants. For determination and expression of emotions by the sample set we tried to analyze the responses provided by the people of that particular location. The implementation has been done with the help of IBM Statistics SPSS software. Initially, we have determined the number of neighbors, that is, $k=3$ for each facilities respectively.

During implementation, whenever a new data object (case) is presented, Euclidean Distance is used to compute to the distance of new object (cases) from each of the objects (cases) in the model and place it into the class (or category) that contains the greatest number of nearest neighbors. It is the distance between point's $\mathrm{p}$ and $\mathrm{q}$. It is actually the length of the line segment connecting them $(\overline{p q})$. If $\mathrm{C}_{1}=\left(\mathrm{p}_{1}, \mathrm{p}_{2}, \mathrm{p}_{3}, \mathrm{p}_{\mathrm{n}}\right)$ and $\mathrm{C}_{2}=\left(\mathrm{q}_{1}, \mathrm{q}_{2}, \mathrm{q}_{3}, \mathrm{q}_{\mathrm{n}}\right)$ are two data objects. Then, the distance between the data objects can be given as:

$$
\begin{gathered}
d(p, q)=\sqrt{\left(b_{1}-a_{1}\right)^{2}+\left(b_{2}-a_{2}\right)^{2}+\cdots+\left(b_{n}-a_{n}\right)^{2}} \\
\mathrm{~d}(\mathrm{p}, \mathrm{q})=\sqrt{\sum_{i=0}^{n}\left(\mathrm{q}_{\mathrm{i}}-\mathrm{p}_{\mathrm{i}}\right)^{n}}
\end{gathered}
$$

The results obtained by applying $\mathrm{k}$ nearest neighbor algorithm on various facility data using IBM SPSS tool can be given in the form of tables and charts for each facilities:

i. Case Processing Summary Table: It summarizes the number of cases (data objects) included and excluded in the analysis in total and by training and testing (holdout) samples.

ii. Predictor Space Chart: It is an interactive graph of the feature space (or subspace, if there are more than 3 features). Each axis represents a feature in the model and location of points in the chart shows the values of these features for cases in the training and testing (or holdout) partitions. It classifies the data object based on their nearest neighbours in accordance with three predictor variables. It is a $3 \mathrm{D}$ interactive chart that identifies the three nearest neighbour to the data object. It is also termed as Feature Space Chart, where features are attributes of a data object that can be represented in a multidimensional space.

Predictor Importance Chart: It is a chart that helps us to focus our modelling efforts on the variables (or featured attributes) that matter most and consider dropping or ignoring those that matter least by indicating the relative importance of each variable (or featured attribute) in estimating the classifier model. Since, the values are relative, the sum of values of all variables (or featured attributes) on the display is 1.0. It does not relate to accuracy of the classifier model. It is also termed as Feature Importance (for a predictor). It is calculated by the ratio of the error rate or sum of squares of the classifier model with the predictor removed from the model to the error rate or sum of squares error for the full model.

iii. Classification Table: It displays the cross classification of observed versus predicted values of the categorical target attribute by partition.

iv. Error Summary Table: It displays the error associated with the model; sum of squares for a continuous target and the error rate for a categorical target.
In this paper, the result obtained for three facilities are shown as below:

\subsection{Industrialization Facility Data}

It consists of 10 numbers of questions. Q1 is about necessity of industrialization at Majitar. Q2 is for getting an opinion about whether the increase in industrialization is leading to environmental pollution at Majitar. Q3 and Q4 are for need of industrialization for economic growth and whether there is a need of more industries to be established at Majitar. Q5 is all about different types of industries that are supported by the people of Majitar. Q5 has 10 types of industries namely; Q51 refers to engineering and machinery industry, Q52 refer to tourism industry, Q53 refer to transportation industry, Q54 refer to chemical industry, Q55 refers to IT and ITES industry, Q56 refer to textile industry, Q57 refer to agro based industry, Q58 refers to food and beverage industry, Q59 refer to mineral based industry and Q510 refer to forest based industry. Q6, Q7 and Q8 are for getting an opinion from the people of Majitar about whether development in industrialization will increase in employment in that location, whether it will help in increasing the real estate value of the land and should government provide more land for industrial development respectively. Q9 is about whether there is any development so far in this facility. Q10 is about present condition of this facility.

The number of cases overall classified in training data sample is 54 and in testing is 46 . The number of valid cases is 100 , with no invalid (or excluded) cases as shown in table 1 .

Table 1. Case Processing Summary for Industrialization Facility Data

Case Processing Summary

\begin{tabular}{|c|c|c|}
\hline & N & Percent \\
\hline Sample Training & 54 & $54.0 \%$ \\
Holdout & 46 & $46.0 \%$ \\
Valid & 100 & $100.0 \%$ \\
Excluded & 0 & \\
Total & 100 & \\
\hline
\end{tabular}

In training sample data set, the percentage of correctly classified data objects is $38.9 \%$ and incorrectly classified data objects are $61.1 \%$. In testing sample data set, the percentage of correctly classified data objects is $54.3 \%$ and incorrectly classified data objects are $45.7 \%$. The accuracy (or percentage of correctness) of training data sample is $38.9 \%$ and of testing data sample is $54.3 \%$. A class having highest measure of precision (or producer accuracy) is 'Better' in both cases of training and testing samples. A class having highest measure of recall (or user accuracy) is 'Better' in case of training sample and 'Average' and 'Better' in case of testing sample as shown in table 2 and table 3. 
Table 2. Error Summary for Industrialization Facility Data

\begin{tabular}{|l|c|}
\hline \multicolumn{1}{|c|}{ Error Summary } \\
\hline Partition & Percent of Records Incorrectly Classified \\
\hline Training & $61.1 \%$ \\
\hline Holdout & $45.7 \%$ \\
\hline
\end{tabular}

Table 3. Classification Table for Industrialization Facility Data

\begin{tabular}{|c|c|c|c|c|c|c|c|}
\hline \multicolumn{8}{|c|}{ Classification Table } \\
\hline \multirow{2}{*}{ Partition } & \multirow{2}{*}{ Observed } & \multicolumn{6}{|c|}{ Predicted } \\
\hline & & Average & Bad & Better & Good & Worst & $\begin{array}{l}\text { Percent } \\
\text { Correct }\end{array}$ \\
\hline \multirow{6}{*}{ Training } & Average & 6 & 1 & 2 & 3 & 1 & $46.2 \%$ \\
\hline & Bad & 2 & 0 & 2 & 2 & 2 & $0.0 \%$ \\
\hline & Better & 0 & 1 & 15 & 2 & 0 & $83.3 \%$ \\
\hline & Good & 5 & 0 & 2 & 0 & 2 & $0.0 \%$ \\
\hline & Worst & 5 & 0 & 1 & 0 & 0 & $0.0 \%$ \\
\hline & $\begin{array}{l}\text { Overall } \\
\text { Percent }\end{array}$ & $33.3 \%$ & $3.7 \%$ & $40.7 \%$ & $13.0 \%$ & $9.3 \%$ & $38.9 \%$ \\
\hline \multirow{7}{*}{$\begin{array}{c}\text { Testing } \\
\text { (Holdout) }\end{array}$} & Average & 7 & 1 & 4 & 4 & 0 & $43.8 \%$ \\
\hline & Bad & 2 & 2 & 0 & 1 & 0 & $40.0 \%$ \\
\hline & Better & 4 & 0 & 11 & 0 & 0 & $73.3 \%$ \\
\hline & Good & 2 & 1 & 0 & 4 & 0 & $57.1 \%$ \\
\hline & Worst & 2 & 0 & 0 & 0 & 1 & $33.3 \%$ \\
\hline & Missing & 0 & 0 & 0 & 0 & 0 & - \\
\hline & $\begin{array}{l}\text { Overall } \\
\text { Percent }\end{array}$ & $37.0 \%$ & $8.7 \%$ & $32.6 \%$ & $19.6 \%$ & $2.2 \%$ & $54.3 \%$ \\
\hline
\end{tabular}

The predictor space chart of industrialization facility data is a lower-dimensional projection of the predictor space, which contains a total of 18 predictors as shown in figure 3. Since, the number of neighbors, $k=3$. Therefore, the three features attributes (or predictors) that are used to build the k-nearest neighbor classifier model (in lower dimension) are Q52 (Tourism industry), Q54 (Chemical industry) and Q58 (Food and beverage industry).

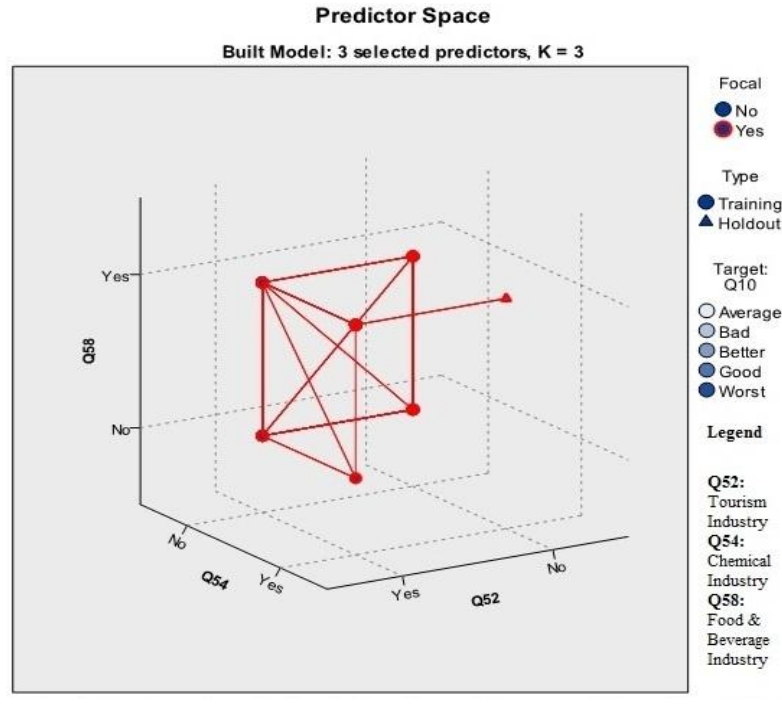

Fig 3: Predictor Space Chart for Industrialization Facility Data

The 10 important feature attributes which are considered by the classifier to have importance in urban development of this facility are: Q58 (Food and beverage industry), Q54 (Chemical industry), Q57 (Agro-based industry), Q56 (Textile industry), Q53 (Transportation industry), Q52 (Tourism industry), Q7 (Development in industrialization will increase in real estate value of the land), Q6 (Development in industrialization will increase in employment), Q4 (Need of more industries to be established) and Q8 (More land should be provided by government for industrial development). The most important amongst them is Q58 (Food and beverage industry) and least important amongst them is Q8 (More land should be provided by government for industrial development) as shown in figure 6 .

Urban Emotions determined for this facility with respect to the expressions (or responses) provided by the people of Majitar are: Since, development in industrialization will increase in employment and real estate value of the land. So, more industries are need to be established and should be add to the locality of Majitar such as food and beverage, chemical, agro-based, textile, transportation and tourism.

\subsection{Shopping Mart Facility Data}

It consists of 6 numbers of questions. Q1 is about availability of shopping mart at Majitar. Q2 gives the number of shopping mart available, and Q3 queries whether shopping mart are necessary at Majitar. Q4 is about availability of sufficient area for establishing more shopping marts at Majitar. Q5 queries about what more facilities should be there in shopping mart. Q5 has a list of ten facilities which are to be newly added to this facility, namely, Q51 is for having food court in that shopping mart; Q52 is for having a vegetable, fruit and fish market in that shopping mart; Q53 is for having a designer stores for clothing and shoes in it; Q54 is for having stores for accessories and household necessities; Q55 is for having a playhouse for children in it; Q56 is for having a game parlor in the shopping mart; Q57 is for having a gym in it; Q58 is for having beauty salons for men and women; Q59 is for having some stores for stationary items and Q510 is for having multiplexes and PVRs in it. Q6 is about present condition of this facility.

The number of cases overall classified in training data sample is 54 and in testing is 44 . The number of valid cases is 98 and 
invalid (or excluded) cases are 2 as shown in table 4 .

Table 4. Case Processing Summary for Shopping Mart Facility Data

Case Processing Summary

\begin{tabular}{|cc|c|c|}
\hline & & N & Percent \\
\hline \multirow{2}{*}{ Sample } & Training & 54 & $55.1 \%$ \\
& Holdout & 44 & $44.9 \%$ \\
Valid & 98 & $100.0 \%$ \\
Excluded & 2 & \\
Total & 100 & \\
\hline
\end{tabular}

In training sample data set, the percentage of correctly classified data objects is $61.1 \%$ and incorrectly classified data objects are $38.9 \%$. In testing sample data set, the percentage of correctly classified data objects is $59.1 \%$ and incorrectly classified data objects are $40.9 \%$. The accuracy (or percentage of correctness) of training data sample is $61.1 \%$ and of testing data sample is $59.1 \%$. A class having highest measure of precision (or producer accuracy) is 'Worst' in case of training sample and 'Good' in case of testing sample. A class having highest measure of recall (or user accuracy) is 'Worst' and 'Good' in case of training sample. A class having highest measure of recall (or user accuracy) is 'Worst' and 'Good' in case of testing sample as shown in table 5 and table 6 .

Table 5. Error Summary for Shopping Mart Facility Data

\begin{tabular}{|l|c|}
\hline \multicolumn{1}{|c|}{ Error Summary } \\
\hline Partition & Percent of Records Incorrectly Classified \\
\hline Training & $38.9 \%$ \\
\hline Holdout & $40.9 \%$ \\
\hline
\end{tabular}

Table 6. Classification Table for Shopping Mart Facility Data

\begin{tabular}{|c|c|c|c|c|c|c|c|}
\hline \multicolumn{8}{|c|}{ Classification Table } \\
\hline \multirow[b]{2}{*}{ Partition } & \multirow[b]{2}{*}{ Observed } & \multicolumn{6}{|c|}{ Predicted } \\
\hline & & Average & Bad & Better & Good & Worst & $\begin{array}{l}\text { Percent } \\
\text { Correct }\end{array}$ \\
\hline \multirow{6}{*}{ Training } & Average & 3 & 0 & 0 & 1 & 7 & $27.3 \%$ \\
\hline & Bad & 0 & 2 & 0 & 1 & 4 & $28.6 \%$ \\
\hline & Better & 0 & 1 & 0 & 0 & 1 & $0.0 \%$ \\
\hline & Good & 2 & 0 & 0 & 12 & 2 & $75.0 \%$ \\
\hline & Worst & 0 & 0 & 0 & 2 & 16 & $88.9 \%$ \\
\hline & $\begin{array}{l}\text { Overall } \\
\text { Percent }\end{array}$ & $9.3 \%$ & $5.6 \%$ & $0.0 \%$ & $29.6 \%$ & $55.6 \%$ & $61.1 \%$ \\
\hline
\end{tabular}

\begin{tabular}{|c|c|c|c|c|c|c|c|}
\hline \multirow{7}{*}{$\begin{array}{c}\text { Testing } \\
\text { (Holdout) }\end{array}$} & Average & 1 & 1 & 0 & 0 & 6 & $12.5 \%$ \\
\hline & Bad & 1 & 2 & 0 & 0 & 6 & $22.2 \%$ \\
\hline & Better & 0 & 0 & 0 & 0 & 1 & $0.0 \%$ \\
\hline & Good & 0 & 0 & 0 & 9 & 1 & $90.0 \%$ \\
\hline & Worst & 0 & 1 & 0 & 1 & 14 & $87.5 \%$ \\
\hline & Missing & 0 & 0 & 0 & 0 & 0 & - \\
\hline & $\begin{array}{l}\text { Overall } \\
\text { Percent }\end{array}$ & $4.5 \%$ & $9.1 \%$ & $0.0 \%$ & $22.7 \%$ & $63.6 \%$ & $59.1 \%$ \\
\hline
\end{tabular}

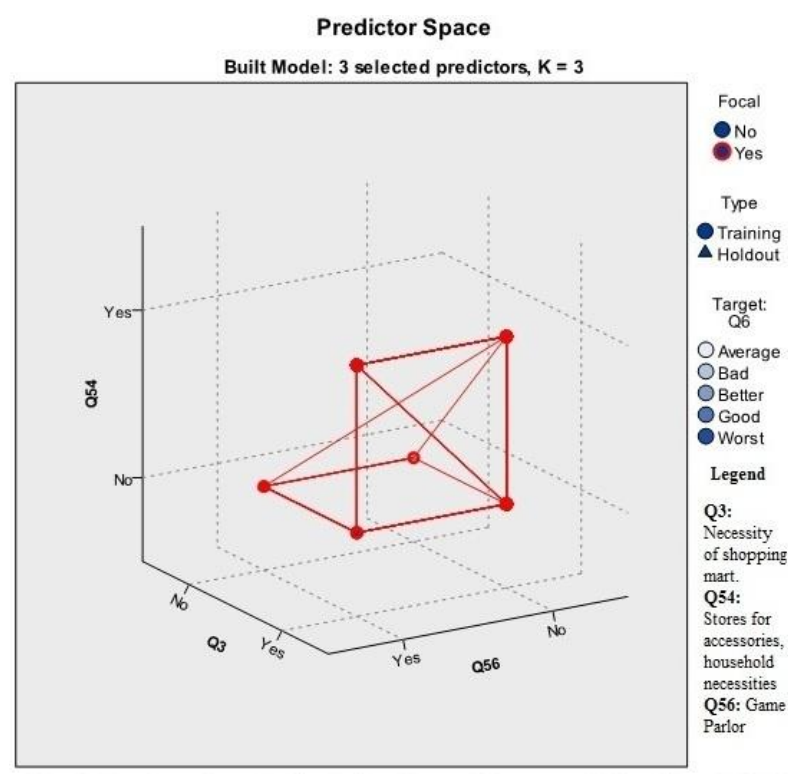

Fig 4: Predictor Space Chart for Shopping Mart Facility Data

The predictor space chart of shopping mart facility data is a lower-dimensional projection of the predictor space, which contains a total of 14 predictors as shown in figure 4 . Since, the number of neighbors, $k=3$. Therefore, the three features attributes (or predictors) that are used to build the k-nearest neighbor classifier model (in lower dimension) are Q3 (Necessity of shopping mart), Q54 (Stores for accessories and household necessities) and Q56 (Game Parlor).

The 10 important feature attributes which are considered by the classifier to have importance in urban development of this facility are: Q56 (Game parlor), Q54 (Stores for accessories, household necessities), Q3 (Necessity of shopping mart), Q57 (Gym), Q53 (Designer stores for clothing and shoes), Q4 (Availability of sufficient area for establishing shopping mart), Q2 (No. of shopping marts available), Q1 (Availability of shopping mart), Q58 (Beauty salons for men and women) and Q55 (Playhouse for children). The most important amongst them is Q56 (Game parlor) and least important amongst them is Q55 (Playhouse for children) as shown in figure 7 .

Urban Emotions determined for this facility with respect to the expressions (or responses) provided by the people of Majitar are: Since, less number of shopping mart facilities are available at Majitar, so, there is a necessity of shopping mart at Majitar. More facilities such as game parlor, stores for 
accessories, household necessities, gym, designer stores for clothing and shoes, beauty salons for men and women and playhouse for children should be add to the locality of Majitar.

\subsection{Transportation Facility Data}

It consists of 12 numbers of questions. Q1 and Q2 queries whether a participant owns a vehicle, if yes, then how many vehicles are owned. Q3 is about availability of public transport at Majitar. Q4 is for the need of three wheeler public transport at Majitar. Q5 is about availability of enough parking facility at Majitar. Q6 is about the present road condition. Q7 queries whether there is a frequent occurrence of road accidents. Q8 is for need of building up new speed breakers in order to avoid road accidents. Q9 is for the need of more attention to be drawn in road safety. Q10 is about availability of government funding regarding this facility. Q11 is about whether there is any development so far in this facility. Q12 is about present condition of this facility.

The number of cases overall classified in training data sample is 54 and in testing is 46 . The number of valid cases is 100 and no invalid (or excluded) cases are there as shown in table 7.

Table 7. Case Processing Summary for Transportation Facility Data

Case Processing Summary

\begin{tabular}{|cc|c|c|}
\hline & & N & Percent \\
\hline \multirow{2}{*}{ Sample } & Training & 54 & $54.0 \%$ \\
& Holdout & 46 & $46.0 \%$ \\
Valid & 100 & $100.0 \%$ \\
Excluded & 0 & \\
Total & 100 & \\
\hline
\end{tabular}

In training sample data set, the percentage of correctly classified data objects is $55.6 \%$ and incorrectly classified data objects are $44.4 \%$. In testing sample data set, the percentage of correctly classified data objects is $43.2 \%$ and incorrectly classified data objects are $56.8 \%$. The accuracy (or percentage of correctness) of training data sample is $55.6 \%$ and of testing data sample is $43.2 \%$. A class having highest measure of precision (or producer accuracy) is 'Average' in case of training sample and 'Good' in cases of testing sample. A class having highest measure of recall (or user accuracy) is 'Good' and 'Average' in cases of training sample and is 'Good' in case of testing sample as shown in table 8 and table 9 .

Table 8. Classification Table for Transportation Facility Data

\begin{tabular}{|c|c|c|c|c|c|c|c|c|}
\hline \multicolumn{7}{|c|}{ Classification Table } \\
\hline \multirow{2}{*}{ Partition } & \multirow{2}{*}{ Observed } & \multicolumn{7}{c|}{ Predicted } \\
\cline { 3 - 8 } & Average & Bad & Better & Good & Worst & $\begin{array}{l}\text { Percent } \\
\text { Correct }\end{array}$ \\
\hline \multirow{2}{*}{ Training } & Average & 13 & 1 & 0 & 3 & 0 & $76.5 \%$ \\
\cline { 3 - 8 } & Bad & 4 & 1 & 1 & 2 & 0 & $12.5 \%$ \\
\hline
\end{tabular}

\begin{tabular}{|c|c|c|c|c|c|c|c|}
\hline & Better & 0 & 0 & 0 & 6 & 0 & $0.0 \%$ \\
\hline & Good & 3 & 0 & 4 & 16 & 0 & $69.6 \%$ \\
\hline & Worst & 0 & 0 & 0 & 0 & 0 & $0.0 \%$ \\
\hline & $\begin{array}{l}\text { Overall } \\
\text { Percent }\end{array}$ & $37.0 \%$ & $3.7 \%$ & $9.3 \%$ & $50.0 \%$ & $0.0 \%$ & $55.6 \%$ \\
\hline & Average & 7 & 0 & 2 & 10 & 0 & $36.8 \%$ \\
\hline & Bad & 1 & 0 & 0 & 1 & 0 & $0.0 \%$ \\
\hline & Better & 4 & 0 & 1 & 1 & 0 & $16.7 \%$ \\
\hline Testing & Good & 4 & 1 & 1 & 11 & 0 & $64.7 \%$ \\
\hline & Worst & 0 & 0 & 0 & 0 & 0 & $0.0 \%$ \\
\hline & Missing & 0 & 0 & 0 & 0 & 0 & - \\
\hline & $\begin{array}{l}\text { Overall } \\
\text { Percent }\end{array}$ & $36.4 \%$ & $2.3 \%$ & $9.1 \%$ & $52.3 \%$ & $0.0 \%$ & $43.2 \%$ \\
\hline
\end{tabular}

Table 9. Error Summary for Shopping Mart Facility Data

\begin{tabular}{|l|c|}
\hline \multicolumn{2}{|c|}{ Error Summary } \\
\hline Partition & Percent of Records Incorrectly Classified \\
\hline Training & $44.4 \%$ \\
\hline Holdout & $56.8 \%$ \\
\hline
\end{tabular}

The predictor space chart of transportation facility data is a lower-dimensional projection of the predictor space, which contains a total of 11 predictors as shown in figure 5. Since, the number of neighbors, $\mathrm{k}=3$. Therefore, the three features attributes (or predictors) that are used to build the k-nearest neighbor classifier model (in lower dimension) are Q2 (No. of vehicles owned), Q8 (New speed breakers are needed to be built to avoid road accidents) and Q10 (Availability of government funding).

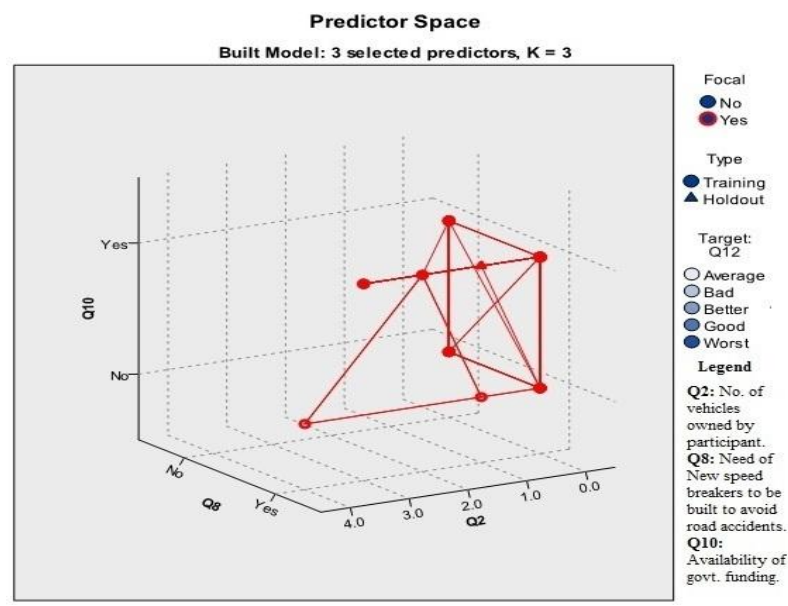

Fig 5: Predictor Space Chart for Transportation Facility Data 
Urban Emotions determined for this facility with respect to the expressions (or responses) provided by the people of Majitar are: From the present road condition, we find that there is frequent occurrence of road accidents, so, more attention are need to be drawn in road safety and new speed breakers are need to be built in order to avoid accidents at Majitar. From the development so far, we find that there is less availability of public transport at Majitar, so, three wheeler public transports should be added to the transportation facility at Majitar. More government funding should be provided for the same to the locality of Majitar.

\section{APPLICATIONS}

There are various application areas of Urban Emotions. It helps in urban safety, settlements, planning, settlements and development. It is useful for traffic planning and people centric tourism. It may be used for assessing previous planning measures. It can be used to improve the quality of living of citizens.

\section{CONCLUSION}

Urban emotion is becoming one of the major areas of research that aims at quality planning and urban settlement prior to its implementation for the betterment of citizens and humanity at large. From the results of a supervised learning approach KNearest Neighbor Classifier algorithm, it is observe that the classifier finds out 10 important featured attribute in each facility which will effect in urban planning, development and urbanization at Majitar. More focus should be provided to featured attribute which is considered as most important by the classifier when the number of neighbors is $k=3$. By analyzing the results, we get featured attributes which has more importance will effect in urban development and those featured attributes are said to have the best response than the other attributes of each facilities. Development should be made to those featured attributes in basis of their importance in urban planning and development. From this study, we can conclude that people of Majitar have demanded improvement as well as development in each facility. They have suggested many features which are need to be included at various facilities available at this locality. Thus, Urban Emotions can act as new information layers within planning processes and determining it using a supervised learning approach will helps in understanding urbanization and in urban planning. In future, it will help in implementing the concept of 'Smart City' at Majitar, which will lead to better sustainability.

\section{Predictor Importance}

Target: $\mathbf{Q 1 0}$

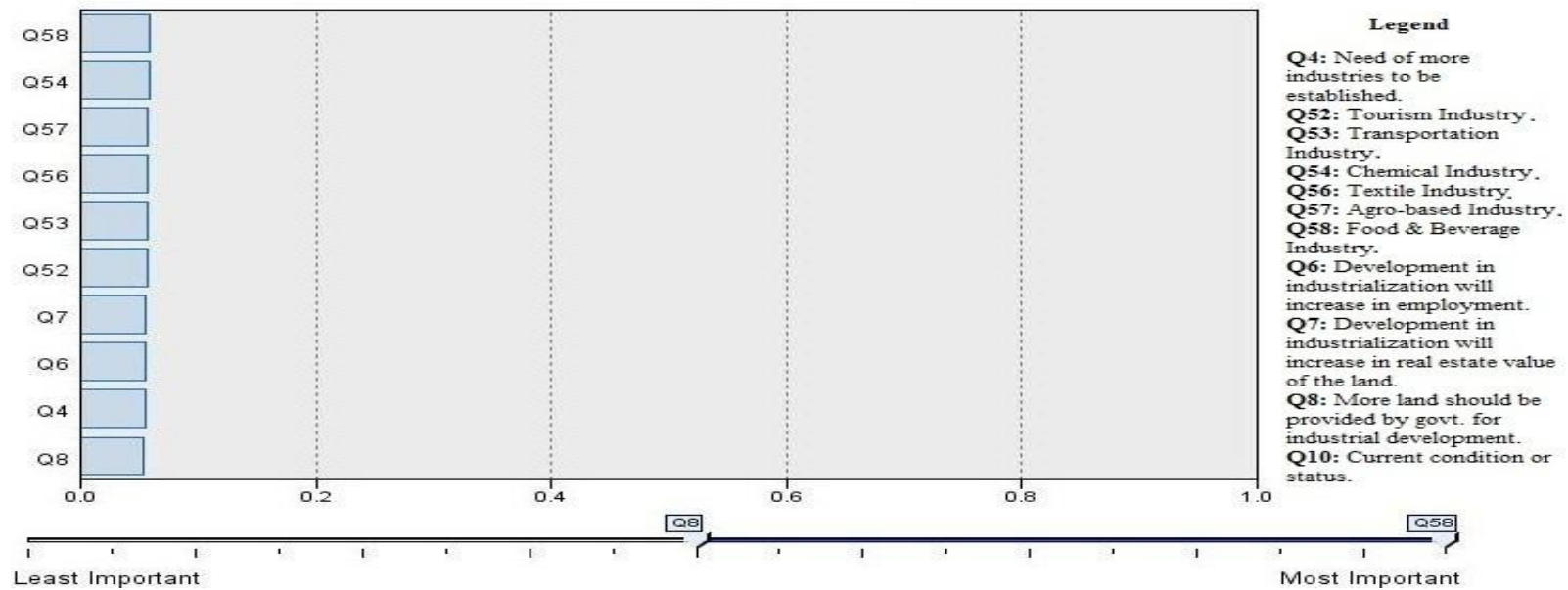

Fig 6: Predictor Importance for Industrialization Facility Data

Predictor Importance

Target: Q6

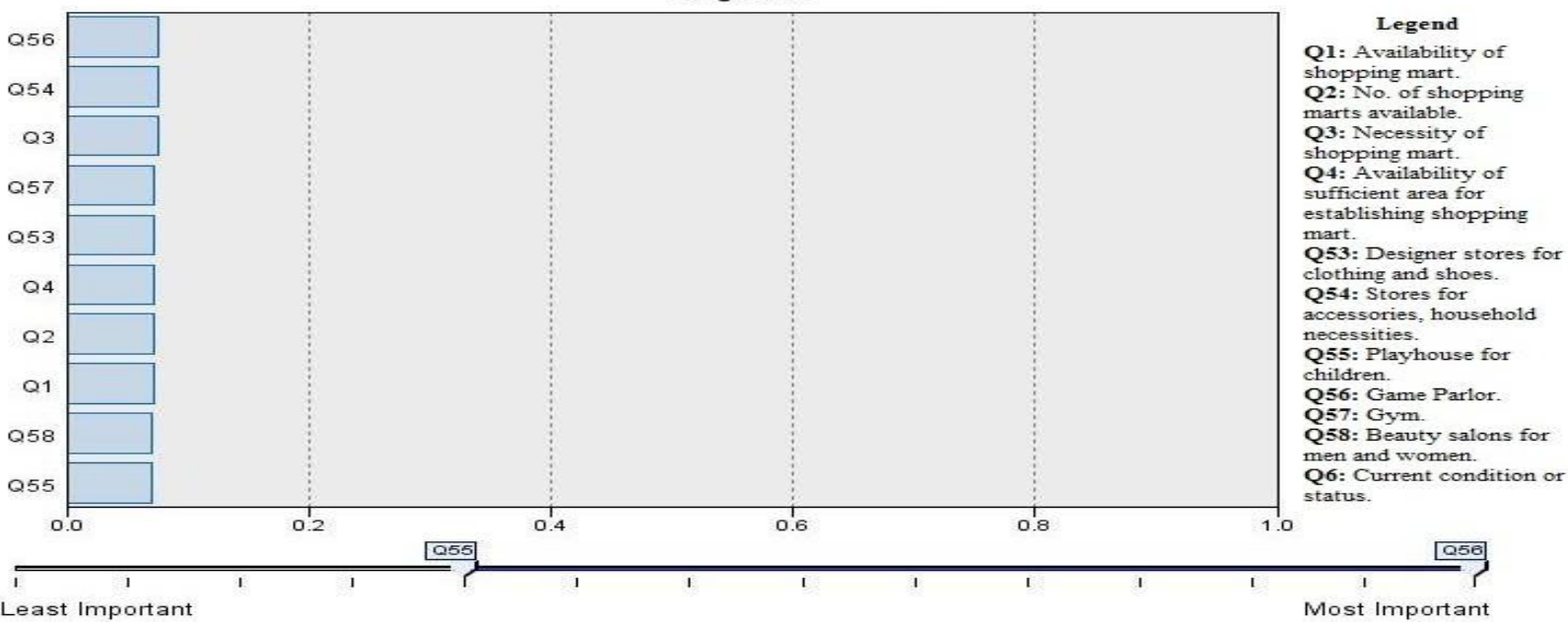

Fig 7: Predictor Importance for Shopping Mart Facility Data 


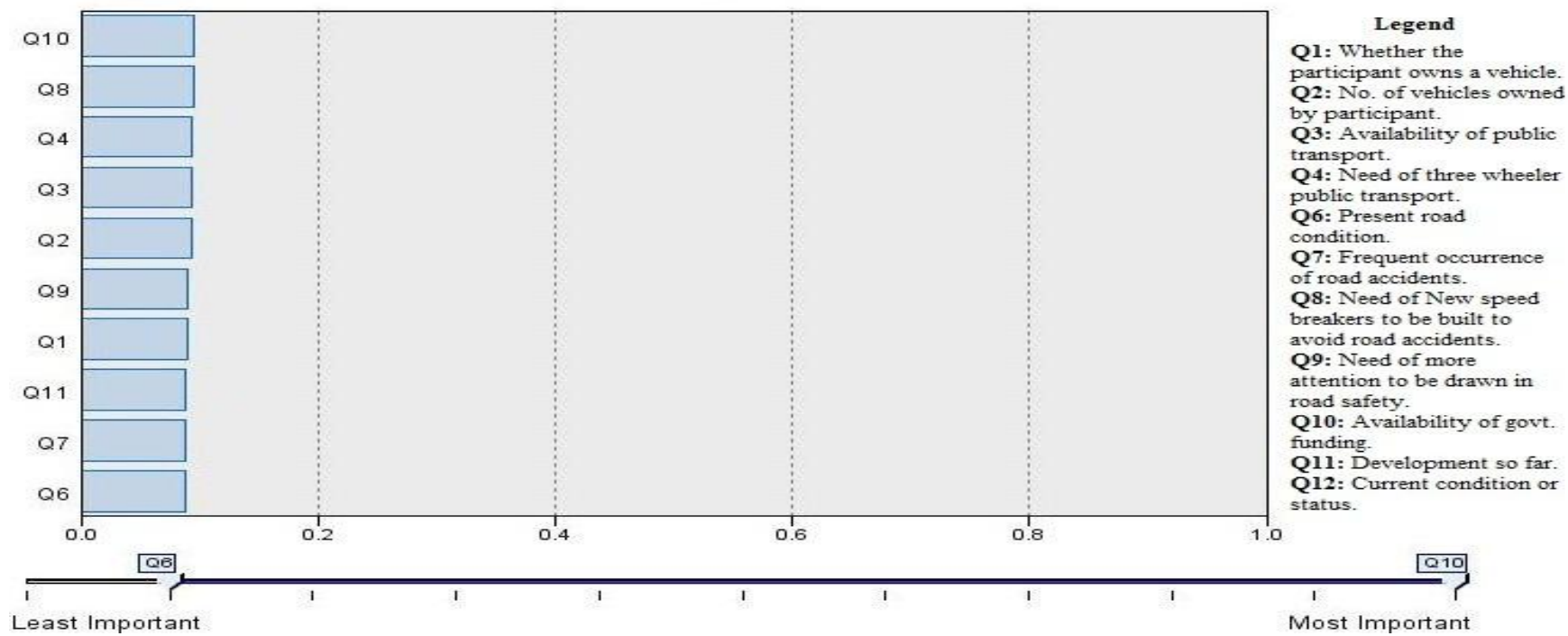

Fig 8: Predictor Importance for Transportation Facility Data

\section{REFERENCES}

[1] Supriya Choudhury, Mohan P. Pradhan, S. K. Kar, "A Survey on Determining Urban Emotions using Geo-Data Classification: A Case Study around Majitar, East District, Sikkim", International Journal of Computer Applications, (0975 - 8887), Volume 135 - No.2, February, 2016, ISBN: 973-93-80891-05-5.

[2] Peter Zeile, Bernd Resch, Linda Dorrzapf, Jan-Philipp Exner, Gunter Sagl, Anja Summa, Martin Sudmanns, Urban Emotions-Tools of Integrating People's Perception into Urban Planning, Conference Proceedings REAL CORP 2015 Tagungsband, 5-7 May 2015, Ghent, Belgium. ISBN: 978-3-9503110-8-2 (CD-ROM); ISBN: 978-3-9503110-9-9 (Print).

[3] Peter Zeile, Bernd Resch, Jan-Philipp Exner and Gunther Sagl, Urban Emotions Benefits and Risks in Using Human Sensory Assessment for the Extraction of Contextual Emotion Information in Urban Planning, Springer International Publishing, 2015.

[4] Bernd Resch, Martin Sudmanns, Gunther Sagl, Anja Summa, Peter Zeile, and Jan-Philipp Exner, Crowdsourcing Physiological Conditions and Subjective Emotions by Coupling Technical and Human Mobile Sensors, GI_Forum - Journal for Geographic Information Science, 1-2015, Berlin, ISBN 978-3-87907558-4, ISSN 2308-1708, doi:10.1553/giscience2015s514.

[5] Gunther Sagl, Bernd Resch, and Thomas Blaschke, Contextual Sensing: Integrating Contextual Information with Human and Technical Geo-Sensor Information for Smart Cities, Open Access Sensors, 2015, 15, 1701317035; DOI: 10.3390/s150717013, ISSN 1424-8220.
[6] Bernd Resch, Anja Summa, Gunther Sagl, Peter Zeile, Jan-Philipp Exner, Urban Emotions-Geo-Semantic Emotion Extraction from Technical Sensors, Human Sensors, Springer International Publishing, 2014.

[7] Chrysaida-Aliki Papadopoulou and Maria Giaoutzi, Crowd-sourcing as a Tool for Knowledge Acquisition in Spatial Planning”, Future Internet 2014, 6, 109-125; ISSN 1999-5903, doi:10.3390/fi6010109.

[8] Benjamin S. Bergner, Jan-Philipp Exner, Martin Memmel, Rania Raslan, Dina Taha, Manar Talal, Peter Zeile,"Human Sensory Assessment Methods in Urban Planning - a Case Study in Alexandria", Conference Proceedings REAL CORP 2013, Tagungsband, 20-23 May 2013, Rome, Italy, ISBN: 978-3-9503110-4-4 (CDROM); ISBN: 978-3-9503110-5-1 (Print).

[9] Bernd Resch, "People as Sensors and Collective SensingContextual Observations Complementing Geo-Sensor Network Measurements", Springer International Publishing, 2013.

[10] Peter Zeile, Martin Memmel, Jan-Philipp Exner, “A New Urban Sensing and Monitoring Approach: Tagging the City with the RADAR SENSING App", Reviewed Paper of Conference Proceedings REAL CORP 2012, Tagungsband, 14-16 May 2012, Schwechat, ISBN: 9783-9503110-2-0 (CD-ROM); ISBN: 978-3-9503110-3-7 (Print).

[11] https://en.wikipedia.org/wiki/Knearest_neighbors_algorit $\mathrm{hm}$.

[12] https://en.wikipedia.org/wiki/Majitar 